\title{
Factors associated with high compliance/feasibility during iron and folic acid supplementation in a tribal area of Madhya Pradesh, India
}

\author{
Tapas Chakma*, Pinnamneni Vinay Rao and Pradeep Kumar Meshram
}

Regional Medical Research Centre for Tribals (Indian Council of Medical Research), Nagpur Road, Garha, Jabalpur 482003, Madhya Pradesh, India

Submitted 17 January 2011: Final revision received 14 April 2012: Accepted 20 April 2012: First published online 28 May 2012

\begin{abstract}
Objective: To study the feasibility of iron and folic acid (IFA) supplementation among tribal adolescent girls and identify factors associated with high compliance. Design: Intervention study with IFA supplementation among tribal adolescent girls of Bijadandi block, Mandla district, Madhya Pradesh, India. Girls ( $n$ 274) from twelve villages randomly selected out of 100 potential villages received daily tablets containing iron (III) hydroxide polymaltose complex equivalent to $100 \mathrm{mg}$ of elemental $\mathrm{Fe}$ and $350 \mu \mathrm{g}$ of folic acid (commercially available as Feritas tablets, marketed by Intas Pharmaceutical Ltd, India). IFA was given for $100 \mathrm{~d}$ and supervised by school teachers and anganwadi workers. Compliance was measured using cards and interviews.

Setting: Community-based iron supplementation programme.

Subjects: Tribal adolescent girls aged 12-19 years.

Results: In total 233 girls completed the study. Prevalence of anaemia was reduced from $94 \%$ at baseline to $69 \%$ after the intervention. Compliance rate ( $>80$ tablets) was $89 \%$. Minor side-effects were reported by three girls, yet they consumed $>80$ tablets. Factors associated with compliance included fasting during the local festival $\left(\chi^{2}=72 \cdot 74\right.$, df $\left.3 ; P<0 \cdot 0001\right)$ and counselling $\left(\chi^{2}=72 \cdot 74\right.$, df 3 ; $P<0 \cdot 0001)$. Other qualitative factors like social mobilization, timely supply of tablets, quality of tablets (blister pack) and availability of teachers and anganwadi workers were also associated with the compliance and feasibility.

Conclusions: High compliance indicates that IFA supplementation with tablets is feasible among the tribal adolescent girls of Bijadandi block, Mandla district.
\end{abstract}

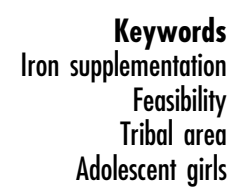

Iron-deficiency anaemia (IDA) is a problem of serious public health significance, given its impact on psychological and physical development behaviour and work performance. It is the most prevalent nutritional problem in the world today, affecting more than 2 billion people ${ }^{(1)}$. Prevalence of IDA in India ranges from $38 \%$ to $72 \%$ depending on age and sex ${ }^{(2)}$. IDA among tribal communities is believed to be very common due to their cerealbased diet ${ }^{(3)}$.

In the state of Madhya Pradesh, India, the prevalence of anaemia was reported as $72 \cdot 0 \%$ among girls aged $12-14$ and $74 \cdot 8 \%$ among girls aged $15-17$ years $^{(4)}$. According to WHO, a prevalence of IDA of more than $40 \%$ is considered a public health concern. The high prevalence of IDA among adolescent girls in Madhya Pradesh suggests the need for intervention.

The National Nutritional Anaemia Prophylaxis Programme of the Government of India has been supplementing adolescent girls with iron and folic acid (IFA) in several states. However, in Madhya Pradesh, this programme remains to be implemented. In this context, a study was undertaken to evaluate the feasibility of IFA supplementation (100 mg of elemental Fe and $350 \mu \mathrm{g}$ of folic acid daily for $100 \mathrm{~d}$; commercially available as Feritas tablets, marketed by Intas Pharmaceutical Ltd, India) among tribal adolescent girls aged 12-19 years in Mandla district of Madhya Pradesh.

The present study was conducted to evaluate the impact of IFA supplementation in Mandla district, Madhya Pradesh on anaemia prevalence and the feasibility and compliance rate under programme conditions.

\section{Methodology}

\section{Study design and sampling procedure}

A community-based intervention study was carried out, using baseline and post-intervention sample collection for $\mathrm{Hb}$ concentration to determine the prevalence of anaemia. 
The cluster sampling method was used to select the study villages. Once a village was selected, all households with an adolescent girl aged 12-19 years had an equal chance of participating in the study.

\section{Sample size}

As per the 2001 census records of the local sub-district unit, the population was 63022. Using the 'Right Size' software (Centers for Disease Control and Prevention, Atlanta, GA, USA) and considering the cluster sampling design, cluster size of twenty (average number of eligible adolescent girls in a village) assuming $70 \%$ prevalence of IDA, with 95\% confidence coefficient and $\pm 10 \%$ confidence interval, 0.02 rate of homogeneity with a design effect of $1 \cdot 38$, a total of 120 adolescent girls from six clusters (villages) was required. In order to identify factors associated with IDA, we doubled the sample size. Allowing for a non-response of $10 \%$, the final sample size was 264 adolescent girls. Since we anticipated only about twenty-five adolescent girls in a cluster (village), to get 264 adolescent girls, in total about twelve clusters were thus required.

\section{Inclusion and exclusion criteria}

All adolescent girls who were mildly or moderately anaemic and also willing girls without anaemia whose $\mathrm{Hb}$ concentration was $>12 \mathrm{~g} / \mathrm{dl}$ were included in the study. According to the study protocol girls with severe anaemia were to be excluded, as they would require a therapeutic dose of iron. After the baseline data collection all girls with severe anaemia and their parents insisted to be included in the supplementation, as they could not go to the district hospital for treatment which was about $70 \mathrm{~km}$ away. Therefore, as we found it unethical that these girls would not receive treatment owing to economic and logistic reasons, all girls with severe anaemia were also included. Adolescent girls with sickle cell disease, thalassaemia or who were pregnant at the time of the survey were excluded from the study.

\section{Data collection}

\section{Techniques and tools}

Data regarding side-effects and reasons for noncompliance were collected from the adolescent girls by a trained interviewer using a semi-structured questionnaire. The questionnaire also gathered information on demographic, socio-economic, anthropometric and dietary factors. A detailed clinical examination was carried out by the principal investigator to record various clinical signs and symptoms of anaemia. After inclusion in the study, a $20 \mu \mathrm{l}$ blood sample was collected from each girl for $\mathrm{Hb}$ determination using the cyanmethaemoglobin method. Blood samples were put on Whatman no. 1 filter paper, sealed in a small plastic bag, packed in a plastic envelope, stored in a refrigerator at $4-8^{\circ} \mathrm{C}$ before analysis and analysed within a week of collection. One day's training was given to all field investigators and laboratory technicians who worked on the project. As a quality control measure every fifteenth blood sample was collected twice and crosschecked by the National Nutrition Monitoring Bureau, National Institute of Nutrition, MP Unit Laboratory.

\section{Supervision and monitoring}

Every $10 \mathrm{~d}$, supervision was done by school teachers and anganwadi workers by pill counting. Cross-checking was done by the principal investigator or other team members from the main laboratory. After supervision and crossverification next week's tablets were distributed. Efforts were made not to visit any study village on the local market day as our visit might interfere with the girls' activities.

All adolescent girls who consumed >80 IFA supplements out of a total of 100 were considered 'compliers' and those who consumed $\leq 80$ tablets were considered 'non-compliers'.

\section{Feasibility}

Feasibility of the project was defined a priori as 50-60\% compliance among the study participants for supplementation.

\section{Data analysis}

Data analysis was done using the Epi Info 2003 package (Centers for Disease Control and Prevention) and statistical tests of significance were done using the StatPac Statistics Calculator (www.statpac.com).

\section{Etbical clearance}

The detailed study protocol was submitted to and approved by the Institutional Ethics Committee of the Regional Medical Research Centre for Tribals, Jabalpur.

\section{Results}

Table 1 summarizes the sociodemographic characteristics of the studied adolescent girls, including age, caste and factors related to IDA, specifically food habits and distance of the studied villages from a health centre. About one-third (34.3\%) of the girls were in the 14-15 years age range, 98\% of them practised Hindu religion and all of them were schedule tribe. About half ( $52 \%$ ) of the studied girls were residing within $5 \mathrm{~km}$ of a health centre.

A total of 274 adolescent girls were registered for the study. The distribution of anaemia among the adolescent girls at baseline and post-intervention is shown in Table 2. The proportion of anaemic girls decreased to $69 \cdot 1 \%$ from $93 \cdot 8 \%\left(\chi^{2}=51 \cdot 38 ; 95 \%\right.$ CI $\left.3 \cdot 73,12 \cdot 39 ; P<0 \cdot 00001\right)$ as a result of IFA supplementation. At post-intervention only 233 girls were available for the evaluation. The distribution curve of $\mathrm{Hb}$ concentration before and after the intervention is shown in Fig. 1. 
Table 1 Sociodemographic characteristics of the study participants: tribal adolescent girls aged 12-19 years ( $n$ 274), Mandla district, Madhya Pradesh, India

\begin{tabular}{lc}
\hline Characteristic & Distribution (\%) \\
\hline Age (years) & \\
$12-13$ & $27 \cdot 7$ \\
$14-15$ & $34 \cdot 3$ \\
$16-17$ & $26 \cdot 6$ \\
$18-19$ & $11 \cdot 3$ \\
Religion & \\
Hindu & $98 \cdot 0$ \\
Muslim & $2 \cdot 0$ \\
Christian & - \\
Sikh & - \\
Caste & \\
Schedule tribe & $98 \cdot 0$ \\
Schedule caste & - \\
Others & $2 \cdot 0$ \\
Food habits & $31 \cdot 0$ \\
Vegetarian & $69 \cdot 0$ \\
Occasional non-vegetarian & - \\
Non-vegetarian & \\
Distance from health centre & $52 \cdot 0$ \\
$\quad 5$ km & $48 \cdot 0$ \\
$\quad 5 \mathrm{~km}$ & \\
\hline
\end{tabular}

Table 2 Distribution according to anaemia status at baseline and post-intervention: tribal adolescent girls aged $12-19$ years, Mandla district, Madhya Pradesh, India

\begin{tabular}{lccccc}
\hline \multirow{2}{*}{ Anaemia status } & \multicolumn{2}{c}{ Baseline } & & \multicolumn{2}{c}{ Post-intervention } \\
\cline { 2 - 3 } \cline { 6 - 7 } & $n$ & $\%$ & & $n$ & $\%$ \\
\hline Normal $(\mathrm{Hb}>12 \mathrm{~g} / \mathrm{dl})$ & 17 & $6 \cdot 2$ & & 72 & $30 \cdot 9$ \\
Anaemic $(\mathrm{Hb} \leq 12 \mathrm{~g} / \mathrm{dl})$ & 257 & $93 \cdot 8^{*}$ & & 161 & $69 \cdot 1^{*}$ \\
Total & 274 & $100 \cdot 0$ & & 233 & $100 \cdot 0$ \\
\hline
\end{tabular}

*Statistically significant $\chi^{2}=51 \cdot 38 ; 95 \% \mathrm{Cl} 3.73,12 \cdot 39 ; P<0.00001$.

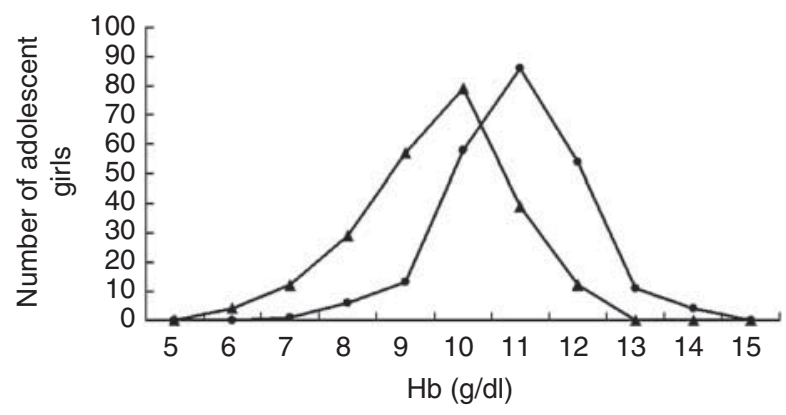

Fig. 1 Distribution of $\mathrm{Hb}$ levels at baseline $(-\boldsymbol{\Delta}-, n 274)$ and post-intervention (- - n 233) in the study participants: tribal adolescent girls aged 12-19 years, Mandla district, Madhya Pradesh, India

\section{Estimation of compliance}

In present study the overall compliance rate, i.e. the proportion of adolescent girls who consumed $>80$ tablets, was $88 \cdot 8 \%$. Only $1 \cdot 3 \%$ of the girls consumed $<60$ tablets, while $12 \cdot 5 \%$ consumed 60-80 IFA tablets.

Out of the total 233 adolescent girls who were available for the post-intervention evaluation, only three girls reported minor-side effects (e.g. gas in the stomach) and one girl reported vomiting. Despite the side-effects all three girls consumed $>80$ tablets, therefore the sideeffects experienced did not influence compliance negatively. The majority $(61 \cdot 8 \%)$ of the adolescent girls missed tablets due to the fasting they practised during the $9 \mathrm{~d}$ 'Navratri' festival. During festival days adolescent girls were absent from school and did not take any supplements. About $10 \%$ of the adolescent girls missed some doses due to illness like fever, and about $15 \%$ missed some doses due to forgetfulness. Only twenty-nine $(12 \cdot 4 \%)$ adolescent girls did not miss any doses.

\section{Factors associated with bigh compliance}

One factor which might have contributed to the high compliance in the present study is health worker qualifications. All twelve workers in the study were carefully selected. More than $58 \%$ of the workers were less than 40 years of age, $66 \cdot 7 \%$ were graduates and $25 \cdot 0 \%$ were postgraduates. Only one anganwadi worker was educated up to higher secondary. Training was provided to all workers including details on the background, rationale, objectives and various activities to be carried out by them. Training enabled them to perform their role effectively. As all workers resided in the allocated villages, the distribution of tablets to adolescent girls was effectively maintained without any difficulty. Of the total of twelve workers, nine were teachers and distributed the tablets on a daily basis to the adolescent girls. Three anganwadi workers delivered tablets on a weekly basis.

Regarding the various activities to be performed, all twelve workers counted pills from the previous week. They also distributed the pills for the next week. Of the twelve workers, eight of them also facilitated the treatment for side-effects by counselling.

\section{Discussion}

In the present study we observed a very high rate of compliance, i.e. $89 \%$, to IFA supplementation among tribal adolescent girls of Mandla district, Madhya Pradesh. Similar high compliance under programme conditions similar to our study was reported by Kotecha et al. ${ }^{(5)}$ in 2002 among rural and tribal adolescent girls of Gujarat. Like other authors ${ }^{(6,7)}$ we used school teachers as supervisors for IFA supplementation as they can positively influence their students for compliance better than anybody else. Additionally, we used anganwadi workers as supervisors only to those adolescent girls who were not going to school and we also used standardized methods of compliance checking, i.e. by pill counting, which yielded better compliance. A search of available literature showed that the majority of studies on supplementation were carried out among pregnant women and pre-school children. There are very few studies on 
adolescent girls or tribal adolescent girls that actually measured the compliance rate. In a study carried out in Bangladesh among pregnant women, the compliance of non-supervised iron supplementation was $68 \%$ after 11 weeks $^{(8)}$. The authors reported that the longer the duration of treatment, the poorer the compliance rate. The higher compliance rate in our study could be attributed to proper training, timely supply of tablets, fewer side-effects of tablets and the close supervision of workers. In spite of side-effects three adolescent girls had compliance of more than $80 \%$. Thus side-effects may not be a reason for non-compliance ${ }^{(9)}$, although numbers are small. After the initial distribution of tablets many adolescent girls were found not to be consuming the tablets. On enquiry, workers reported that many of the adolescent girls were complaining of menstrual abnormalities like scanty periods, dysmenorrhoea, etc. Subsequently every tenth day supervision and group counselling was carried out by the principal investigator in selected villages in the presence of mothers and teachers. This helped in removing the myths among the adolescent girls, ultimately improving their compliance. In our study we also found that one of the major causes (62\%) of missing tablets was fasting due to local festivals like 'Navratri' and 'Teeja'. Such reasons for missing doses have not been reported earlier. Although 'Navratri' festival is celebrated all over the country, different zones have different socio-cultural practices. In central India, especially in rural areas, people observe fasting (only fruit meal) for $9 \mathrm{~d}$. The schools also close during this period, and for a couple of days prior to and after the festival school attendance remains very low. Hence this factor needs to be considered when planning future interventions. Another cause of missing doses was absence from school. Similar observations were also reported from the studies carried out in Peru ${ }^{(10)}$.

Social mobilization at the beginning of the project, involving teachers, anganwadi workers, village elders and local leaders, was of great help in terms of acceptability of the project. During social mobilization adolescent girls were also informed about the possible side-effects of the tablets. This was done as a result of lessons learnt from the Tamil Nadu experience, where such a programme was withheld due to inadequate social mobilization. This was done in every village. The side-effects were also mentioned in the consent form which was read out to the villagers in their local language which made them understand it better.

During the entire study period close monitoring was done not only by the tablet providers also by the principal investigator and other team members. This helped us in identifying bottlenecks for the implementation and thus instituting remedial measures to overcome the same.

Repeated group counselling by the tablet providers and the principal investigator to the adolescent girls helped in removing myths like iron tablets cause menstrual irregularities'. Group counselling also helped the teachers in improving their knowledge on anaemia, which in turn enabled them to convince the adolescent girls to adhere to the programme.

On the basis of the present results it is thus recommended that IFA supplementation should be initiated among these adolescent tribal girls.

\section{Acknowledgements}

The project was supported by the Micronutrient Malnutrition Initiative Group, Centers for Disease Control and Prevention (Atlanta, GA, USA). No author has any conflict of interest. T.C. conceived, planned and executed the project and prepared the first manuscript draft; P.V.R. and P.K.M. assisted in execution, data analysis and finalization of the manuscript. The authors wish to thank Professor M.D. Gupte, former Director of the National Institute of Epidemiology (NIE), Chennai and Dr Vidya Ramachandran, NIE for their suggestions; and Dr Neeru Singh, Director, Regional Medical Research Centre for Tribals, Jabalpur for her support and encouragement.

\section{References}

1. Beard JL (2000) Effectiveness and strategies of iron supplementation during pregnancy. Am J Clin Nutr $\mathbf{7 1}$, 1288-1294.

2. Choudhury P \& Vir S (1994) Prevention and strategies for control of iron deficiency anaemia. In Nutrition in Children - Developing Country Concerns, pp. 492-524. [HPS Sachdev and P Choudhury, editors]. New Delhi: Cambridge University Press.

3. World Health Organization (1994) Report of the WHO/ UNICEF/UNU Consultation on Indicators and Strategies for Iron Deficiency and Anaemia Program. Geneva: WHO.

4. National Nutrition Monitoring Bureau, National Institute of Nutrition (2003) Prevalence of Micronutrient Deficiencies. NNMB Technical Report no. 22. Hyderabad: Indian Council of Medical Research.

5. Kotecha PV, Pate RZ, Karkar PD et al. (2002) Impact Evaluation of Adolescent Girls' Anaemia Reduction Programme in Vadodara District. A Project Report. Gujarat: Medical College, Vadodara.

6. Kotecha PV, Nirupam S \& Karkar PD (2009) Adolescent girls' anaemia control programme, Gujarat, India. Indian J Med Res 130, 584-589.

7. Tee E-S, Kandiah M, Awin N et al. (1999) School administered weekly iron-folate supplements improve hemoglobin and ferritin concentration in Malaysian adolescent girls. Am J Clin Nutr 69, 1249-1256.

8. Ekstorm E-C, Ziauddin Hyder SM, Mushtaque A et al. (2002) Efficacy and trial effectiveness of weekly and daily iron supplementation among pregnant women in rural Bangladesh: disentangling the issues. Am J Clin Nutr 76, 1392-1400.

9. Anshu S, Kanti P \& Visweswara RK (2000) Identification of an appropriate strategy to control anaemia in adolescent girls of poor communities. Indian Pediatr 37, 261-267.

10. Zaveleta N, Respicio G \& Garcia T (2000) Efficacy and acceptability of two iron supplementation schedules in adolescent school girls in Lima, Peru. J Nutr 130, 2S Suppl., 462S-464S. 